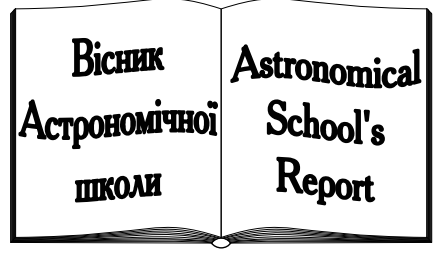

ISSN 1607-2855

Том $1 \cdot$ № $2 \cdot 2000 \quad$ C. $51-55$

UDC 528

\title{
A note on the temporal trend of point positions in the Ukraine area
}

\section{D.A. Marchenko}

State Geodetic Enterprise “WestGeodesCartography”, Lviv, Ukraine

In the development of a standard model of the tectonic plate motion NNR-NUVEL1 the non-linear form of such model was proposed with standard modeling of a temporal trend in the linear form. One version of this model in the Ukraine area was based on weekly determinations of positions of GPS permanent points (within time interval near 3 years).

ПРО ЧАСОВИЙ ТРЕНД ПОЛОЖЕНЬ ГЕОДЕЗИЧНИХ ПУНКТІВ В РЕГІОНІ УКРАЇНИ. МарченКо Д.О. - Для розвитку стандартної моделі NNR-NUVEL1 руху тектонічних плит запропонована ї̈ нелінійна форма 3 моделюванням вікового тренду в рамках традичійної лінійної моделі. На основі щяотижневих визначень координат перманентних GPS-пунктів побудований варіант такої моделі для регіону Украӥни.

О ВРЕМЕННОМ ТРЕНДЕ ПОЛОЖЕНИЙ ГЕОДЕЗИЧЕСКИХ ПУНКТОВ В РЕГИОНЕ УКРАИНЫ. МарченКо Д.А. Для развития стандартной модели NNR-NUVEL1 движения тектонических плит предложена ее нелинейная форма с моделированием векового тренда в рамках традиционой линейной модели. На основе еженедельных определений координат перманентных GPS-пунктів построен вариант такой модели для региона Украины.

\section{INTRODUCTION}

As well know an application of modern high-precision positioning requires the consideration of certain geodynamical effects for an achievement of necessary accuracy. The Earth's tectonic plate motion is one of such effects. Nowadays it is recommended to represent these motions (on a global scale) by the well-known model NNR-NUVEL1 (see, IERS Conventions, 1996). According to this model the position vector $\mathbf{p}(t)$ of a point for some moment of time $t$ may be obtained in the linear formulation from the expression:

$$
\mathbf{p}(t)=\mathbf{p}_{0}+\dot{\mathbf{p}}\left(t-t_{0}\right)
$$

where $\mathbf{p}_{0}=\mathbf{p}\left(t_{0}\right)$ is the position vector of the same point for the certain initial epoch $t_{0}$ and

$$
\dot{\mathbf{p}}=\left[\begin{array}{ccc}
0 & -\dot{\omega}_{3} & \dot{\omega}_{2} \\
\dot{\omega}_{3} & 0 & -\dot{\omega}_{1} \\
-\dot{\omega}_{1} & \dot{\omega}_{3} & 0
\end{array}\right] \cdot \mathbf{p}_{0},
$$

where $\dot{\omega}_{1}, \dot{\omega}_{2}, \dot{\omega}_{3}$ are time variations of rotation angles around the axes $O X, O Y, O Z$, respectively.

Clearly, these expressions can be based on the linearization of well-known Helmert transformation (Hofmann-Wellenhof, at al., 1992)

in the restricted time-dependent form

$$
\mathbf{p}=\mathbf{D}+\mu \cdot \mathbf{Q}(\xi, \eta, \zeta) \mathbf{p}_{0}
$$

$$
\mathbf{p}(t)=\mathbf{Q}(\xi(t), \eta(t), \zeta(t)) \mathbf{p}_{0},
$$

where $\mathbf{D}$ is the shift vector, $\mu$ is the scale, $\mathbf{Q}(\xi, \eta, \zeta)$ is the rotation matrix $\mathbf{Q}(\xi(t), \eta(t), \zeta(t))$, which is described sequential rotations around the corresponding axes 


$$
\mathbf{Q}(\xi(t), \eta(t), \zeta(t))=\mathbf{R}_{z}(\zeta(t)) \mathbf{R}_{y}(\eta(t)) \mathbf{R}_{x}(\xi(t)),
$$

where

$$
\mathbf{R}_{x}(\xi)=\left[\begin{array}{ccc}
1 & 0 & 0 \\
0 & \cos \xi & \sin \xi \\
0 & -\sin \xi & \cos \xi
\end{array}\right], \quad \mathbf{R}_{y}(\eta)=\left[\begin{array}{ccc}
\cos \eta & 0 & -\sin \eta \\
0 & 1 & 0 \\
\sin \eta & 0 & \cos \eta
\end{array}\right], \quad \mathbf{R}_{z}(\zeta)=\left[\begin{array}{ccc}
\cos \zeta & \sin \zeta & 0 \\
-\sin \zeta & \cos \zeta & 0 \\
0 & 0 & 1
\end{array}\right] .
$$

Naturally, in the relationship (4) $\mathbf{D}=0$ and $\mu=1$ were assumed and adopted. The model (1)-(2) was used before for the determination of $\dot{\omega}_{1}, \dot{\omega}_{2}, \dot{\omega}_{3}$ in the frame of such standard liner problem in the Ukraine area (O.Abrikosov and D.Marchenko, 2000; O.Abrikosov and D.Marchenko, 2000a). But in practice the liner model (1)-(2) may be not enough in view of non-liner dependence in (5)-(6). For this reason, the main aim of this paper is the construction and application of the non-liner model (4)-(6) with the same temporal (secular) trend of the rotation angels as in (1)-(2).

\section{SOLUTION OF NON-LINER PROBLEM}

Instead of the model (1)-(2) we will use directly the representation (4) with the next model for angles

$$
\xi(t)=\dot{\omega}_{1}\left(t-t_{0}\right), \quad \eta(t)=\dot{\omega}_{2}\left(t-t_{0}\right), \quad \zeta(t)=\dot{\omega}_{3}\left(t-t_{0}\right),
$$

which were adopted here as the linear functions of time. Thus, we have tried to construct the linear model of temporal variations of point positions (especially for the Ukraine area), based on the non-linear formulation or the formulas (4)-(6) by iterations.

As a result, we will rewrite (4) in view of (7) and get the following dependence

$$
\mathbf{p}(t)=\mathbf{Q}\left(\dot{\omega}_{1}, \dot{\omega}_{2}, \dot{\omega}_{3}, t\right) \mathbf{p}_{0},
$$

where the parameters $\dot{\omega}_{1}, \dot{\omega}_{2}, \dot{\omega}_{3}$ are considered as definable values. Next step is the linearization of the expression (8). The expansion (8) into a standard Taylor series gives

$$
\mathbf{p}(t)=\left(\mathbf{Q}\left(\dot{\omega}_{1}, \dot{\omega}_{2}, \dot{\omega}_{3}, t\right)+\frac{\partial \mathbf{Q}}{\partial \dot{\omega}_{1}} \cdot d \dot{\omega}_{1}+\frac{\partial \mathbf{Q}}{\partial \dot{\omega}_{2}} \cdot d \dot{\omega}_{2}+\frac{\partial \mathbf{Q}}{\partial \dot{\omega}_{3}} \cdot d \dot{\omega}_{3}\right) \cdot \mathbf{p}_{0},
$$

were $d \dot{\omega}_{1}, d \dot{\omega}_{2}, d \dot{\omega}_{3}$ is the corresponding changes of $\dot{\omega}_{1}, \dot{\omega}_{2}, \dot{\omega}_{3}$, which should be determined. The necessary derivatives in (9) from $\mathbf{Q}$ with respect to the parameter $\vartheta$ representing any parameter $\dot{\omega}_{1}, \dot{\omega}_{2}, \dot{\omega}_{3}$ can be computed (in the generalized form) to take into account (5):

$$
\frac{\partial \mathbf{Q}}{\partial \vartheta}=\mathbf{R}_{Z} \mathbf{R}_{Y} \frac{\partial R_{X}}{\partial \vartheta}+\mathbf{R}_{Z} \frac{\partial R_{Y}}{\partial \vartheta} \mathbf{R}_{X}+\frac{\partial R_{Z}}{\partial \vartheta} \mathbf{R}_{Y} \mathbf{R}_{X},
$$

Now the elementary matrix (6) can be represented here in a more simpler form by applying (7). First introducing the notations

$$
\begin{array}{ccc}
\mathbf{R}_{X}^{0}=\left[\begin{array}{lll}
1 & 0 & 0 \\
0 & 0 & 0 \\
0 & 0 & 0
\end{array}\right], & R_{X}^{C}=\left[\begin{array}{lll}
0 & 0 & 0 \\
0 & 1 & 0 \\
0 & 0 & 1
\end{array}\right], & \mathbf{R}_{X}^{S}=\left[\begin{array}{ccc}
0 & 0 & 0 \\
0 & 0 & 1 \\
0 & -1 & 0
\end{array}\right] \\
R_{Y}^{0}=\left[\begin{array}{lll}
0 & 0 & 0 \\
0 & 1 & 0 \\
0 & 0 & 0
\end{array}\right], & R_{Y}^{C}=\left[\begin{array}{lll}
1 & 0 & 0 \\
0 & 0 & 0 \\
0 & 0 & 1
\end{array}\right], & R_{Y}^{S}=\left[\begin{array}{ccc}
1 & 0 & -1 \\
0 & 0 & 0 \\
1 & 0 & 0
\end{array}\right], \\
R_{Z}^{0}=\left[\begin{array}{lll}
0 & 0 & 0 \\
0 & 0 & 0 \\
0 & 0 & 1
\end{array}\right], & \mathbf{R}_{Z}^{C}=\left[\begin{array}{lll}
1 & 0 & 0 \\
0 & 1 & 0 \\
0 & 0 & 0
\end{array}\right], & \mathbf{R}_{Z}^{S}=\left[\begin{array}{ccc}
0 & 1 & 0 \\
-1 & 0 & 0 \\
0 & 0 & 0
\end{array}\right],
\end{array}
$$

we come to the following representation of the expressions for matrixes of the elementary rotations

$$
\mathbf{R}_{X}=\mathbf{R}_{X}^{0}+\mathbf{R}_{X}^{C} \cdot \cos \dot{\omega}_{1}\left(t-t_{0}\right)+\mathbf{R}_{X}^{S} \cdot \sin \dot{\omega}_{1}\left(t-t_{0}\right),
$$




$$
\begin{aligned}
& \mathbf{R}_{Y}=\mathbf{R}_{Y}^{0}+\mathbf{R}_{X}^{C} \cdot \cos \dot{\omega}_{2}\left(t-t_{0}\right)+\mathbf{R}_{Y}^{S} \cdot \sin \dot{\omega}_{2}\left(t-t_{0}\right), \\
& \mathbf{R}_{Z}=\mathbf{R}_{Z}^{0}+\mathbf{R}_{Z}^{C} \cdot \cos \dot{\omega}_{3}\left(t-t_{0}\right)+\mathbf{R}_{Z}^{S} \cdot \sin \dot{\omega}_{3}\left(t-t_{0}\right) .
\end{aligned}
$$

Then, after the differentiation of (14) we get

$$
\begin{aligned}
& \mathbf{R}_{X \dot{\omega}_{1}}=-\mathbf{R}_{X}^{C} \cdot \sin \dot{\omega}_{1}\left(t-t_{0}\right)+\mathbf{R}_{X}^{S} \cdot \cos \dot{\omega}_{1}\left(t-t_{0}\right), \\
& \mathbf{R}_{Y \dot{\omega}_{2}}=-\mathbf{R}_{Y}^{C} \cdot \sin \dot{\omega}_{2}\left(t-t_{0}\right)+\mathbf{R}_{Y}^{S} \cdot \cos \dot{\omega}_{2}\left(t-t_{0}\right), \\
& \mathbf{R}_{Z \dot{\omega}_{3}}=-\mathbf{R}_{Z}^{C} \cdot \sin \dot{\omega}_{3}\left(t-t_{0}\right)+\mathbf{R}_{Z}^{S} \cdot \cos \dot{\omega}_{3}\left(t-t_{0}\right),
\end{aligned}
$$

because the derivatives in (9) admit the next form

$$
\begin{aligned}
& \frac{\partial \mathbf{Q}}{\partial \dot{\omega}_{1}}=\mathbf{R}_{Z} \cdot \mathbf{R}_{Y} \cdot \mathbf{R}_{X \dot{\omega}_{1}} \cdot\left(t-t_{0}\right), \\
& \frac{\partial \mathbf{Q}}{\partial \dot{\omega}_{2}}=\mathbf{R}_{Z} \cdot \mathbf{R}_{Y \dot{\omega}_{2}} \cdot \mathbf{R}_{X} \cdot\left(t-t_{0}\right), \\
& \frac{\partial \mathbf{Q}}{\partial \dot{\omega}_{3}}=\mathbf{R}_{Z} \cdot \mathbf{R}_{Y} \cdot \mathbf{R}_{X \dot{\omega}_{1}} \cdot\left(t-t_{0}\right) .
\end{aligned}
$$

Thus the expression (9) can be written as

$$
\begin{aligned}
& \mathbf{P}(t)-\mathbf{Q}\left(\dot{\omega}_{1}, \dot{\omega}_{2}, \dot{\omega}_{3},\left(t-t_{0}\right)\right) \mathbf{p}_{0}= \\
& =\left(t-t_{0}\right) \cdot\left(d \dot{\omega}_{1} \mathbf{R}_{Z} \mathbf{R}_{Y} \mathbf{R}_{X \dot{\omega}_{1}} \mathbf{p}_{0}+d \dot{\omega}_{2} \mathbf{R}_{Z} \mathbf{R}_{Y \dot{\omega}_{2}} \mathbf{R}_{X} \mathbf{p}_{0}+d \dot{\omega}_{3} \mathbf{R}_{Z \dot{\omega}_{3}} \mathbf{R}_{Y} \mathbf{R}_{X} \mathbf{p}_{0}\right)
\end{aligned}
$$

where

and we get

$$
\mathbf{P}_{\omega_{1}}=d \dot{\omega}_{1} \mathbf{R}_{Z} \mathbf{R}_{Y} \mathbf{R}_{X \dot{\omega}_{1}} \mathbf{p}_{0}, \quad \mathbf{P}_{\omega_{2}}=d \dot{\omega}_{2} \mathbf{R}_{Z} \mathbf{R}_{Y \dot{\omega}_{2}} \mathbf{R}_{X} \mathbf{p}_{0}, \quad \mathbf{P}_{\omega_{3}}=d \dot{\omega}_{3} \mathbf{R}_{Z \dot{\omega}_{3}} \mathbf{R}_{Y} \mathbf{R}_{X} \mathbf{p}_{0}
$$

$$
\mathbf{P}(t)-\mathbf{Q}\left(\dot{\omega}_{1}, \dot{\omega}_{2}, \dot{\omega}_{3},\left(t-t_{0}\right)\right) \mathbf{p}_{0}=\left(t-t_{0}\right)\left(\mathbf{P}_{\omega_{1}} \cdot d \dot{\omega}_{1}+\mathbf{P}_{\omega_{2}} \cdot d \dot{\omega}_{2}+\mathbf{P}_{\omega_{3}} \cdot d \dot{\omega}_{3}\right)
$$

Again we introduce the new notation

$$
\Delta \mathbf{P}=\mathbf{p}\left(t-t_{0}\right)-\mathbf{Q}\left(\dot{\omega}_{1}, \dot{\omega}_{2}, \dot{\omega}_{3},\left(t-t_{0}\right)\right) \mathbf{p}_{0},
$$

and expression (20) can be written now as

$$
\Delta \mathbf{P}=\left(t-t_{0}\right) \cdot\left[\begin{array}{lll}
\mathbf{P}_{\dot{\omega}_{1}} & \mathbf{P}_{\dot{\omega}_{2}} & \mathbf{P}_{\dot{\omega}_{3}}
\end{array}\right] \cdot\left(\begin{array}{c}
d \dot{\omega}_{1} \\
d \dot{\omega}_{2} \\
d \dot{\omega}_{3}
\end{array}\right),
$$

It is evident that the equation (21) is valid for any geodetic point and for any time $t$. As a result, if we know coordinates of $N$ geodetic point for $K$ instant times, the quantities $d \dot{\omega}_{1}, d \dot{\omega}_{2}, d \dot{\omega}_{3}$ can be found on the basis of least squares adjustment by parameters. These quantities $d \dot{\omega}_{1}, d \dot{\omega}_{2}, d \dot{\omega}_{3}$ represent here parameters of the corresponding linearized equation (21) which leads finally to the system of normal equations

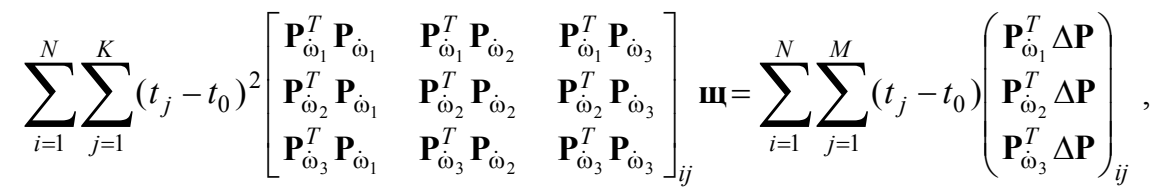

with its solution for one iteration

$$
\mathbf{\Psi}=\left(\begin{array}{l}
d \omega_{1} \\
d \omega_{2} \\
d \omega_{3}
\end{array}\right) .
$$


Table 1. The parameters of the constructed model for secular trend of point position changes

\begin{tabular}{|l|c|c|c|}
\hline \multirow{2}{*}{ Parameters } & \multicolumn{2}{|c|}{ Model } & Differences between 2 models: \\
\cline { 2 - 3 } & $(4)-(6)$ & NNR-NUVEL1 & -0.4695 \\
$\dot{\xi}\left(0.001^{\prime \prime} / \mathrm{yr}\right)$ & $-0.6715 \pm 0.0004$ & -0.202 & +0.3280 \\
$\dot{\eta}\left(0.001^{\prime \prime} / \mathrm{yr}\right)$ & $-0.1660 \pm 0.0002$ & -0.494 & -1.8549 \\
$\dot{\zeta}\left(0.001^{\prime \prime} / \mathrm{yr}\right)$ & $-1.2049 \pm 0.0005$ & +0.650 & . NNR-NUVEL1 \\
\hline
\end{tabular}

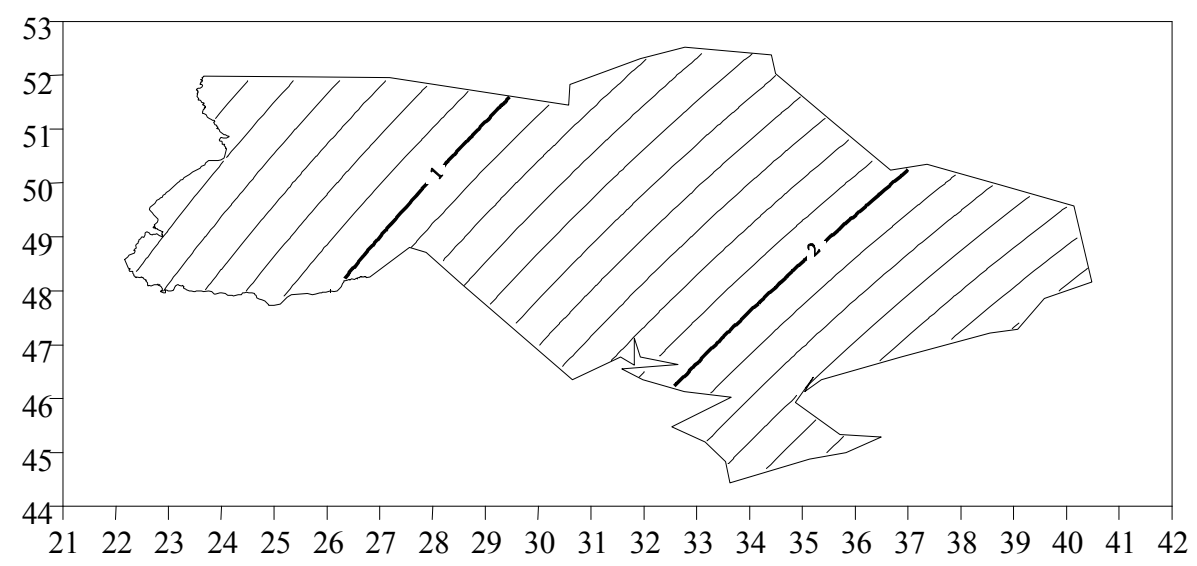

Figure 1. Differences between the constructed model and NNR-NUVEL1 (coordinate $X$ [mm/yr]).

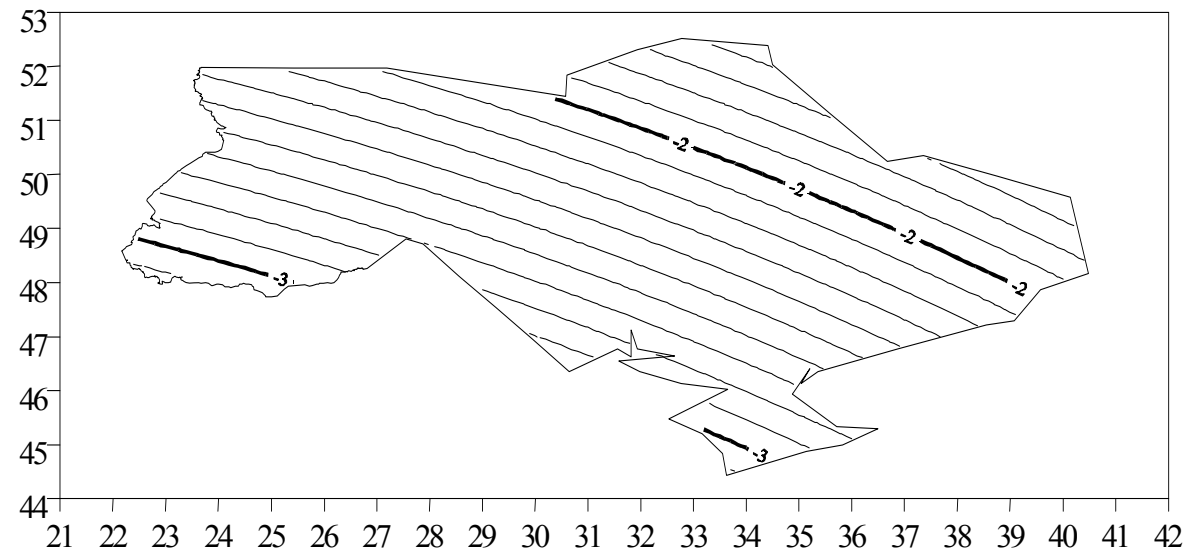

Figure 2. Differences between the constructed model and NNR-NUVEL1 (coordinate $Y$ [mm/yr]).

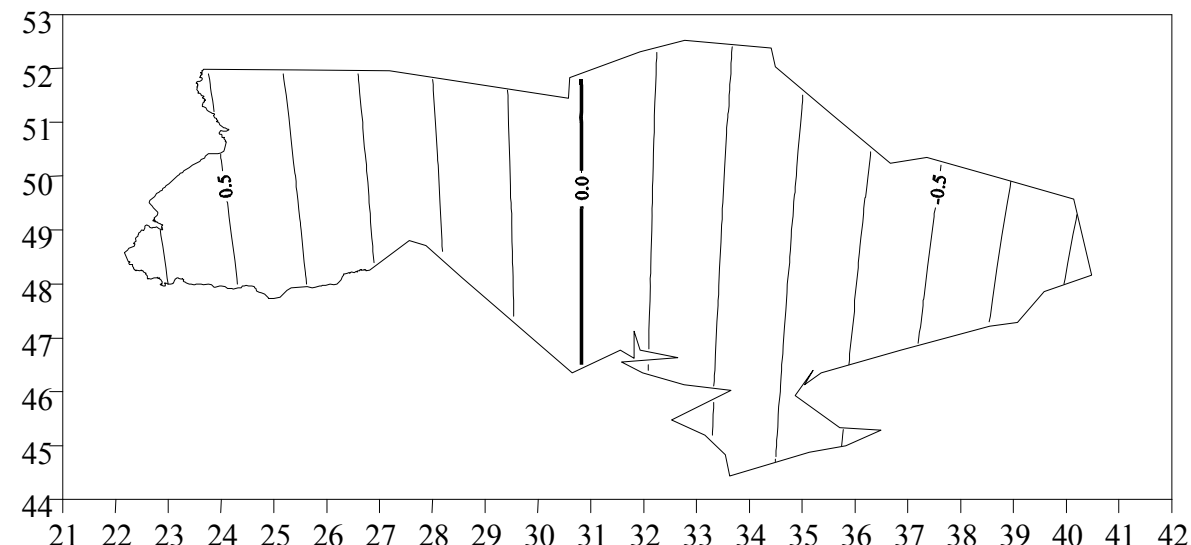

Figure 3. Differences between the constructed model and NNR-NUVEL1 (coordinate $Z$ [mm/yr]). 


\section{MODELLING OF POINT POSITIONS CHANGES IN THE UKRAINE AREA}

Rectangular coordinates of 21 GPS permanent points, which surround the Ukraine (obtained by EUREF Project for GPS permanent points) were taken as initial data for the construction of the model (4)-(6). Most part of points has weekly solutions over time span 3.5 years. Only one permanent point Goloseevo located in the Ukraine area (72 weekly solutions) was used in this study. As a result, the model of non-periodic Earth's surface displacement was constructed especially for Ukraine area. The computation of the parameters $\dot{\omega}_{1}, \dot{\omega}_{2}, \dot{\omega}_{3}$ was done in the frame of above mentioned non-linear problem. These values were obtained from the iterative solution of the normal system (22) that corresponds to least squares adjustment by parameters (23) for every iteration.

Table 1 illustrates the computed values of $\dot{\omega}_{1}, \dot{\omega}_{2}, \dot{\omega}_{3}$ with the corresponding accuracy estimation.. Figure 1, Figure 2, and Figure 3 reflect the differences of rates between the model (4)-(6) and NNR - NUVEL1, which are corresponded to every coordinate $X, Y$, and $Z$. Comparison of the constructed model (4)-(6) with NNRNUVEL1 leads to the conclusion that systematic differences near $3 \mathrm{~mm} / \mathrm{yr}$ in the Ukraine area are hold. More detail, these differences between two models consist the next values: $\delta \dot{x} \approx+2.4 \mathrm{~mm} /$ year,$\delta \dot{y} \approx-3.1 \mathrm{~mm} /$ year , $\delta \dot{z} \approx+0.5 \mathrm{~mm} /$ year. In contrast to our previous study (O.Abrikosov and D.Marchenko, 2000) based on the mathematical model of (1)-(2) type, finally we get the essentially better R.m.s. value of the representation of rates.

1. Abrikosov, O.A. and Marchenko, D.A. (2000) On the model of secular displacements of geodetic points in the Ukraine area. Paper presented at the conference "Modern Achievements of Geodesy". (April, 2000, Lviv), University of Lviv, 2000, 91-95.

2. Abrikosov, O.A. and Marchenko, D.A. (2000a) The Model of non-periodic earth's surface displacement in ukraine area. Paper presented at the EGS XXV General Assembly. (April, 2000, Nice), 2000, p. 227.

3. Hofmann-Wellenhof B., Lichtenegger H., and Collins J. (1992). Global Positioning System. Theory and Practice. Springer-Verlag Wien New York.

4. The IERS Conventions (1996). IERS Technical Note No 21 (D. McCarthy ed.).

Received 20.05.2000 